\title{
Caracterização dos tipos de acidentes de trabalho do ambulatório de Terapia Ocupacional do Hospital do Trabalhador de Curitiba, PR ${ }^{1}$
}

\author{
Marcela de Andrade Balsano ${ }^{a}$, Angela Paula Simonellib \\ a Curso de Terapia Ocupacional, Universidade Federal do Paraná - UFPR, Curitiba, PR, Brasil \\ 'Departamento de Terapia Ocupacional, Universidade Federal do Paraná - UFPR, Curitiba, PR, Brasil
}

\begin{abstract}
Resumo: Os acidentes de trabalho caracterizam-se como o maior agravo à saúde dos trabalhadores brasileiros. A subnotificação dos acidentes de trabalho é ampla no país e dificulta a atuação dos serviços responsáveis pela vigilância dos ambientes de trabalho. Este estudo objetivou identificar e caracterizar a demanda de pacientes vítimas de acidentes de trabalho atendidos no ambulatório de Terapia Ocupacional do Hospital do Trabalhador do Município de Curitiba, PR. A pesquisa caracterizou-se como descritiva exploratória e baseou-se em análise documental. Realizou-se análise documental dos prontuários referentes aos atendimentos realizados no período de janeiro de 2010 a março de 2012, totalizando 1.723 prontuários. Foi adotado como critério de inclusão prontuários que indicassem que o acometimento teve origem em um acidente de trabalho e, como critério de exclusão, aqueles em que o acometimento tivesse outra origem. Dentre o total de prontuários, 497 configuraram lesões por acidentes de trabalho, o que representou $28,8 \%$ do total de atendimentos. Verificou-se a predominância da ocorrência de acidentes de trabalho no gênero masculino, que representou $86,72 \%$ dos atendimentos. Os setores de trabalho que se destacaram com altos índices de ocorrência de acidentes de trabalho foram: construção civil, metalurgia, serviços gerais, transportes e correios e alimentação e os postos de trabalho que apresentaram maiores índices de acidentes foram: auxiliar de produção e operador de máquina. O estudo ainda destacou o desafio do profissional que atua nessa perspectiva de vigilância em saúde do trabalhador, uma vez que são insuficientes os dados coletados pelos serviços de assistência ao trabalhador vítima de acidente de trabalho.
\end{abstract}

Palavras-chave: Acidente de Trabalho, Vigilância em Saúde do Trababalhador, Terapia Ocupacional, Saúde do Trabalhador.

\section{Characterization of the types of work accidents in the ambulatory care Clinic of Occupational Therapy of the Workers' Hospital of Curitiba, Parana State}

\begin{abstract}
Work accidents are characterized as the greatest health problem of Brazilian workers. The underreporting of workplace accidents is extensive in the country, hampering the performance of the services responsible for the supervision of work environments. This study presents the identification and characterization of the demand for work accidents in the ambulatory care clinic of Occupational Therapy of the Workers' Hospital of Curitiba, Parana state. This is a descriptive and exploratory research based on documental analysis. We conducted a bibliographic survey on the subject and a documental analysis of patient files at the ambulatory care clinic from January 2010 to March 2012, totaling 1,723 medical records. The inclusion criterion included all records indicating involvement in work accidents; while the exclusion criterion included records indicating involvement in accidents of other origins. Of the total number of records analyzed, 497 belonged to victims of work accidents, representing $28.8 \%$. Results showed prevalence of occurrence of work accidents in males, representing $86.72 \%$ of the consultations. The following job sectors and workstations presented the highest occurrence of work accidents: civil construction, metallurgy,
\end{abstract}

Autor para correspondência: Angela Paula Simonelli, Departamento de Terapia Ocupacional, Universidade Federal do Paraná, Av. Lothário Meissner, 632, Campus Jardim Botânico, CEP 80210-170, Jardim Botânico, Curitiba, PR, Brasil, e-mail: angelasimonelli@ufpr.br

Recebido em Maio 14, 2013; 1ª revisão em Jul.11, 2013; 2ª revisão em Nov. 14, 2013; Aceito em Dez. 11, 2013 
general services, transports, postal services, and food services; the following jobs showed the highest indices of work accidents: production assistant and machine operator. The study also highlights the challenge of professionals working in the perspective of surveillance of workers' health, because the data collected by the assistance services to victims of work accidents are insufficient.

Keywords: Work Accident, Surveillance of Workers' Health, Occupational Therapy, Occupational Health.

\section{Introdução}

O campo da saúde do trabalhador no Brasil possui raízes nas lutas sociais deflagradas na década de 1970, nas quais os trabalhadores lutavam por melhores condiçóes de trabalho e de vida (DIAS; HOEFEL, 2005). Na década de 1980, com a ênfase na política democrática por parte dos governos, a luta em prol da saúde dos trabalhadores toma forma, pois eles passam a ser considerados como possuidores do saber e não mais apenas consumidores dos serviços ofertados (LOURENÇO; BERTANI, 2007). A expressão saúde do trabalhador passa então a ser considerada um campo da ciência que visa abranger as relaçóes de trabalho e a implicaçáo dele nos processos de saúde-doença (BRASIL, 2005).

A inclusão da saúde do trabalhador no Sistema Único de Saúde (SUS) favoreceu o reconhecimento das condiçôes que agravam a saúde dos trabalhadores nos ambientes e processos de trabalho em uma perspectiva epidemiológica (LOURENÇO; BERTANI, 2007). Grande parte dos atendimentos realizados na rede pública é feito para pessoas vítimas de acidentes de trabalho (SANTANA et al., 2007), portanto as ações de saúde não se restringem apenas a atender os trabalhadores lesionados individualmente mas buscam quantificar o número de pessoas expostas à insegurança e qualificar essas condiçôes para posteriores mudanças (LOURENÇO; BERTANI, 2007).

Atualmente cabe ao Ministério do Trabalho e Emprego, ao Ministério da Previdência e Assistência Social, ao Ministério da Saúde e ao Ministério do Meio Ambiente, bem como aos estados e municípios, a organizaçáo e a oferta dos serviços aos trabalhadores (BRASIL, 2005). Uma das modalidades de atendimento prevista é a assistência ambulatorial, que objetiva atender aos principais problemas de saúde da população, variando, portanto, conforme a regiáo em que se instala (ROCHA, 2002).

O ambiente de trabalho é composto por diversos fatores que afetam a saúde dos trabalhadores e representam risco de acidentes de trabalho. Do ponto de vista legal, o acidente de trabalho é aquele que ocorre pelo exercício do trabalho, a serviço da empresa, que cause lesão corporal, perturbação funcional, doença que cause a perda, redução ou a morte, imutavelmente ou temporariamente da capacidade para o trabalho (LOPES FILHO et al., 1987).

Recentemente, a análise dos acidentes de trabalho tem se desenvolvido na direção da ampliação conceitual; tal desenvolvimento apoia-se nas diferentes formas de entender os fatores relacionados e a logística de origem dos acidentes (VILELA et al., 2007). Segundo Llory (1999), apud Vilela et al. (2007), o acidente de trabalho deve ser considerado um fator determinante no sistema de trabalho e náo apenas como estatística. Nesse sentido, diversos fatores relacionados aos acidentes devem ser considerados e analisados, como a história da organização, as relaçôes de trabalho e interpessoais que a compóem e as situaçôes de trabalho existentes.

O poder público tem como parte de suas atribuiçôes o controle dos acidentes de trabalho, sua prevenção e a promoção da saúde dos trabalhadores. Para a formulação de políticas públicas é necessário a utilização de informações referentes à realidade dos acidentes de trabalho, suas características e determinantes (CORDEIRO et al., 2005). Atualmente inexiste um sistema de informação capaz de unir todas as notificaçôes acerca dos acidentes de trabalho e os setores da economia, impossibilitando assim traçar um perfil epidemiológico da ocorrência dos incidentes laborativos (HENNINGTON; MONTEIRO, 2006).

A caracterização da demanda de acidentes de trabalho justifica-se pelas estatísticas referentes ao Brasil, uma vez que os acidentes de trabalho representam o maior agravo à saúde dos trabalhadores, sendo o país recordista mundial em acidentes de trabalho. Esses acidentes são as principais causas de morte e incapacidade em todo o mundo, atingindo em sua maioria pessoas jovens - esses agravos comprometem a produtividade e, consequentemente, economia do país (SANTANA et al., 2007).

As estatísticas disponíveis acerca de tal realidade são subestimadas, uma vez que há dificuldades na identificação, definição do ocorrido e notificação dos serviços responsáveis pela prevenção desses 
agravos (SANTANA et al., 2007). Os dados oficiais brasileiros são obtidos a partir da emissão da Comunicação de Acidente de Trabalho (CAT), a qual foi desenvolvida pela Previdência Social, cujos fins objetivam a seguridade dos trabalhadores do mercado formal, porém mesmo com o preenchimento de $100 \%$ das notificações frente aos acidentes a subnotificação ainda ocorrerá, uma vez que são várias as classes de trabalhadores que náo se enquadram na obrigatoriedade da notificação (CORDEIRO et al., 2005).

Tal subnotificação entre os trabalhadores do mercado formal dificulta a obtenção das estatísticas referentes ao país ou de determinada regiáo, portanto estudos deste porte colaboram para o conhecimento das atuais estatísticas referentes aos acidentes no Brasil. Destaca-se ainda que normalmente não são considerados os trabalhadores informais nos setores da economia do país, sendo que esses representam $60 \%$ da população economicamente ativa (PEA) nos dias atuais. Se ponderados, podem reduzir a subestimação dos dados que atualmente é de até $90 \%$, bem como auxiliar no conhecimento acerca do impacto desses acidentes na produtividade e dos custos para o governo e para as empresas (CORDEIRO et al., 2005).

A vigilância em saúde do trabalhador propóe açôes voltadas à promoção de saúde, coleta e análise de informação pertinentes às condiçōes de saúde e trabalho, podendo configurar relaçóes intersetoriais entre os equipamentos do SUS e as açôes desenvolvidas, objetivando a prevenção de agravos relacionados ao trabalho (MACHADO, 1997).

O terapeuta ocupacional justifica-se como um profissional articulador nessas açôes, uma vez que visa a prevenção e atua em situações de trabalho concretas. Sofrendo a influência de diversos saberes, configura-se como um profissional de atuação ímpar nessa perspectiva da saúde do trabalhador, uma vez que compreende a relaçáo singular entre o trabalho e a singularidade dos indivíduos que o executam, sendo assim, age considerando todas as particularidades do processo de trabalho e como elas contribuem para a ocorrência dos acidentes (LANCMAN; GHIRARDI, 2002).

Tanto no serviço público como no privado, os terapeutas ocupacionais realizam atos em prol da saúde do indivíduo em atividades de trabalho, atuando diretamente na promoção de saúde, prevenção de acidentes e doenças do trabalho e na reabilitação dos doentes, compondo assim açóes multidisciplinares em equipes multiprofissionais (WATANABE; GONÇALVES, 2004). Se atuante nos serviços ambulatoriais, o profissional obtém um lugar importante na equipe, uma vez que considera as atividades de vida diária, atividades instrumentais de vida diária, criando estratégias de atenção à saúde do trabalhador, visando a diminuição dos agravos advindos dos acidentes (SANTOS, 2004).

A articulaçáo dos serviços de saúde pública com as instituiçóes acadêmicas colabora para o aumento das pesquisas na área da saúde do trabalhador, já que são congregados saberes de diversas teorias, metodologias e profissóes (VILELA, 2011). Dessa forma, este estudo objetivou quantificar e caracterizar a demanda de pacientes vítimas de acidentes de trabalho atendidos no ambulatório de Terapia Ocupacional do Hospital do Trabalhador de Curitiba, PR. Buscou-se realizar um levantamento do perfil sociodemográfico, dos setores e postos de trabalho envolvidos, correlacionando tais estatísticas encontradas com os dados regionais e nacionais equivalentes. Ressalta-se que os estudos nessa área são um desafio cujo fim é entender o funcionamento da atual conjuntura de assistência ao trabalhador no país, bem como a causa que o leva ao atendimento e ao seu afastamento do ambiente em que trabalha (LANCMAN; GHIRARDI, 2002).

\section{Métodos}

A presente pesquisa caracterizou-se como descritiva-exploratória, geralmente utilizada quando a pesquisa objetiva realizar uma aproximaçáo de um fato com hipóteses, estabelecendo as possíveis características de um serviço ofertado e a atuação prática dele (GIL, 2008). Baseou-se na metodologia de análise documental, a qual constitui uma técnica decisiva para trabalhos de investigação realizados a partir de documentos (ABREU, 2001), devido ao potencial informativo do documento e a necessidade de informação dos indivíduos (NASCIMENTO, 2009). Por basear-se na análise documental retrospectiva foi solicitada e concedida pelo Comitê de Ética a dispensa do Termo de Consentimento Livre e Esclarecido (TCLE).

Numa etapa preliminar realizou-se o levantamento da literatura acerca do tema em geral. A coleta de dados foi realizada no ambulatório de Terapia Ocupacional do Hospital do Trabalhador, do município de Curitiba, PR, integrante da Unidade de Reabilitação do Hospital do Trabalhador, e iniciou-se com a tabulaçáo dos dados disponíveis nos prontuários dos sujeitos atendidos entre janeiro de 2010 a março de 2012 
(27 meses), um total de 1,723 prontuários. Foram incluídos nessa análise todos os prontuários dos pacientes atendidos no referido período cuja informação no campo específico da avaliação do serviço de Terapia Ocupacional "mecanismo da lesão" apresentava relação com o trabalho. Foram excluídos da análise os prontuários que no campo "mecanismo da lesão" não apresentavam relação com o trabalho.

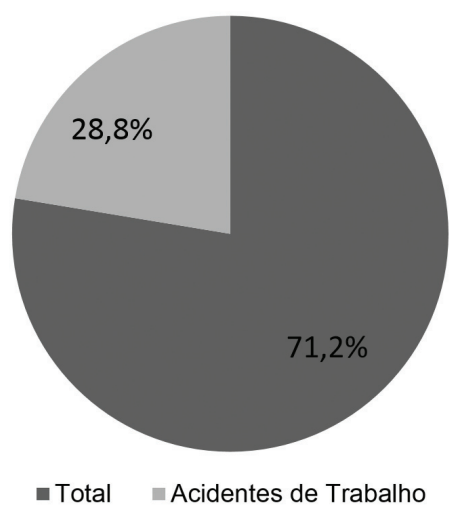

Figura 1. Distribuição dos atendidos no ambulatório de Terapia Ocupacional do Hospital do Trabalhador segundo a ocorrência de acidentes de trabalho. Fonte: Elaborado pelas autoras (2013).
Os dados selecionados para tabulação foram: gênero, idade, diagnóstico, CID, setor ou posto de trabalho. Por fim foi realizada a comparação dos achados com as estatísticas regionais e nacionais, relacionando-os com a literatura publicada.

\section{Resultados}

Dentre o total de 1.723 prontuários analisados, foram classificados os atendimentos feitos às vítimas de acidentes de trabalho, bem como quantificada

Tabela 1. Vítimas de acidente de trabalho segundo gênero e faixa etária.

\begin{tabular}{ccc}
\hline Faixa etária & Masculino & Feminino \\
\hline $10-20$ & 35 & 4 \\
$21-30$ & 127 & 19 \\
$31-40$ & 95 & 22 \\
$41-50$ & 83 & 7 \\
$51-60$ & 49 & 10 \\
$61-70$ & 17 & 2 \\
$71-80$ & 2 & 1 \\
$91-100$ & 1 & \\
Vazias & 22 & 1 \\
Total & 431 & 66 \\
$\%$ & $86,72 \%$ & $13,28 \%$ \\
\hline
\end{tabular}

Fonte: Elaborado pelas autoras (2013).

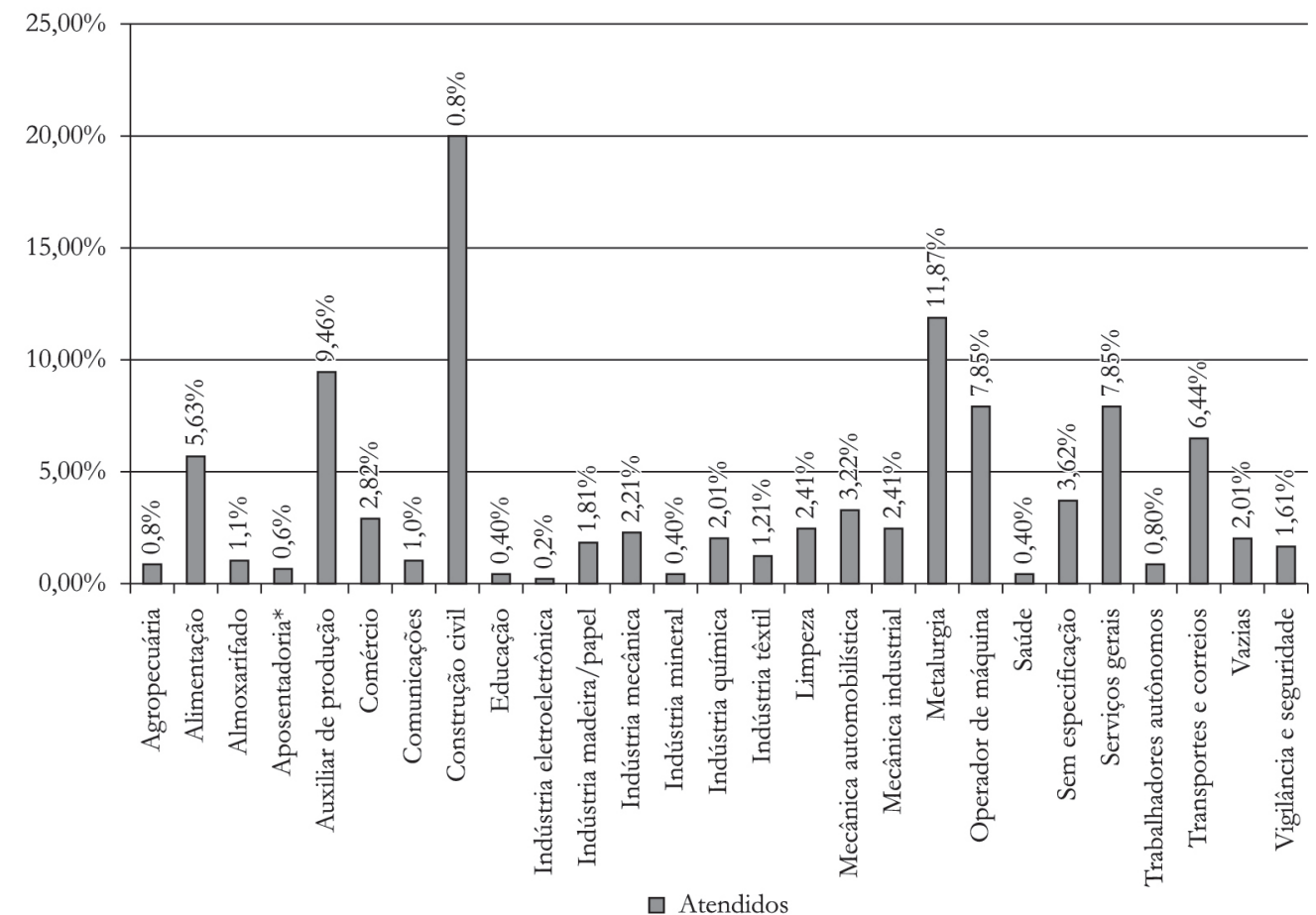

Figura 2. Acidentes de trabalho classificados segundo setores e postos de trabalho. Fonte: Elaborado pelas autoras (2013). 
a ocorrência desses casos conforme setor ou posto de trabalho.

A respeito dos acidentes de trabalho, foram atendidos 497 pacientes, que representam 28,8\% do total de 1.723 (Figura 1).

Com relação aos 497 atendidos vítimas de acidentes de trabalho, o sexo masculino representou $86,72 \%$ dos atendimentos e o feminino $13,28 \%$ do total, conforme Tabela 1 .

Destaca-se que 22 prontuários dos atendidos do sexo masculino e um prontuário de atendido do sexo feminino vítimas de acidente de trabalho não continham a especificação da faixa etária do paciente no campo da avaliação, o qual exigia o preenchimento da "data de nascimento" e "idade".

Os dados obtidos sobre os atendimentos nos diversos setores e postos de trabalho foram sistematizados e quantificados em porcentagem na Figura 2.

Conforme a Figura 2, apresenta-se, a seguir, de forma descrescente, os sete postos ou setores de trabalho que apresentaram destaque durante a tabulação dos dados. Trabalhadores da construção civil representaram 19,92\%; do setor de metalurgia, $11,87 \%$; trabalhadores com o posto de auxiliar de produção representaram 9,46\%; 7,85\% trabalhavam no posto de operador de máquina; $7,85 \%$ de trabalhadores atuavam no setor de serviços gerais; $6,44 \%$ de trabalhadores eram do setor de transportes e correios e os atendidos do setor de alimentação representam 5,63\%.

Destaca-se que 2,01\% dos prontuários analisados não especificavam a atividade laboral praticada pelo paciente, apenas informavam que a causa do atendimento devia-se a acidente de trabalho, bem como 3,82\% náo especificavam o setor ou posto de trabalho do paciente.

\section{Discussão}

Os dados obtidos neste estudo corroboram a afirmação de Wünsch Filho (1999) de que os acidentes de trabalho configuram-se como o maior agravo à saúde dos trabalhadores. A demanda dos acidentados de trabalho atendidos no ambulatório de Terapia Ocupacional do Hospital do Trabalhador foi identificada e caracterizada a fim de que as açóes de vigilância em saúde do trabalhador possam atingir os setores e locais de trabalho que apresentaram altos índices de ocorrência de acidentes de trabalho.

O estado do Paraná possui, aproximadamente, 2,8 milhóes de trabalhadores, oriundos de todos os setores do mercado de trabalho, e, em média, ocorrem 52 mil acidentes de trabalho por ano, que tornam o estado o terceiro em que mais ocorrem acidentes de trabalho por ano (ANUÁRIO..., 2012). Com relação aos 1.723 prontuários analisados, 497 foram de pacientes vítimas de acidente de trabalho, o que representa $28,8 \%$ dos atendimentos realizados no ambulatório de Terapia Ocupacional do Hospital do Trabalhador.

Os setores de trabalho com o maior número de acidentes de trabalho da amostra, no período analisado, foram: construção civil, metalurgia, serviços gerais, transportes e correios e alimentaçáo, e os postos de trabalho com o maior número de acidentes de trabalho foram auxiliar de produção e operador de máquina. Segundo Machado (1997), se reconhecidos os riscos de acidente de trabalho a que estão submetidos os trabalhadores, os mesmos poderão ser prevenidos e tais intervençôes se refletirão sobre as estatísticas apresentadas (MACHADO, 1997).

Verificou-se que 99 atendidos, ou seja, 19,92\% do total de atendimentos realizados a pacientes vítimas de acidentes de trabalho, acidentaram-se na construçấo civil. Dentre os riscos ocupacionais encontrados nas atividades desenvolvidas nesse setor destacam-se: o manejo de equipamentos e máquinas pesadas e perfuro-cortantes, trabalho em grandes alturas, manejo de instalações elétricas, posturas incorretas e alta rotatividade de profissionais devido às precárias condições de trabalho e salário (SANTANA; OLIVEIRA, 2004; IRIART et al., 2008). No estado do Paraná existem cerca de 117 mil trabalhadores na construção civil, sendo que a média de acidentes é de 2,23 a cada 100 trabalhadores. Se comparados aos dados nacionais, os acidentes nesse setor compreendem 7,8\%, em média, por ano dos acidentes que ocorrem nos ambientes de trabalho (ANUÁRIO..., 2012).

Tais dados indicam, conforme o encontrado no estudo realizado, que os riscos existentes na realização das atividades do setor da construçáo civil evidenciam a ocorrência de maiores índices de acidente de trabalho nele em comparação com os demais setores. Vale ressaltar que muitos trabalhadores vítimas de acidente de trabalho, devido à falta da seguridade social, acabam abandonando o tratamento de saúde sem o perfeito reestabelecimento da mesma, dada a necessidade de trabalho para subsistência (IRIART et al., 2008).

Outro setor de trabalho que se destacou no estudo foi o de metalurgia, cujos atendidos somaram 59 dentre o total de 497, representando $11,87 \%$. O ruído e a utilização do maquinário 
sem proteção apresentaram-se como principais fatores determinantes dos acidentes nesse setor (GONÇALVES; DIAS, 2011). Comparativamente com as estatísticas nacionais, o setor representa $1,5 \%$ dos acidentes que ocorrem em um ano, em média. No estado do Paraná esses acidentes ocorreram, em 2009, por exemplo, na proporção de 3,6 a cada 100 trabalhadores (ANUÁRIO..., 2012). Portanto, as atividades de trabalho desenvolvidas no setor de metalurgia apresentam um alto risco de acidentes de trabalho, tanto nos índices nacional e estadual quanto nos achados desta pesquisa.

O posto de trabalho auxiliar de produçáo representou $9,87 \%$ e o posto de trabalho operador de máquina correspondeu a 7,85\% dos atendimentos realizados aos pacientes vítimas de acidente de trabalho. As funções nesses postos podem ser assumidas em diversos setores de trabalho, portanto não foi possível neste estudo especificar a atividade real desenvolvida para que pudessem ser desenvolvidas estratégias preventivas. No decorrer da pesquisa observou-se a ineficiência do protocolo utilizado para a avaliação dos pacientes atendidos no ambulatório de Terapia Ocupacional do Hospital do Trabalhador quanto à dados referentes às características das atividades laborais desenvolvidas pelos pacientes atendidos, pois a forma de avaliação realizada não permitiu a este estudo encontrar dados que se aproximassem mais da realidade dos casos atendidos, uma vez que muitos dos prontuários analisados apresentavam vários campos da avaliação não preenchidos, principalmente a especificação dos referidos postos de trabalho, setor de atuação envolvido.

Ressalte-se a importância de sensibilizar as profissionais terapeutas ocupacionais do serviço para o correto preenchimento do protocolo de avaliação próprio do ambulatório, bem como para a reelaboração do tópico mecanismo e histórico da lesão, para que a atividade em desenvolvimento durante a lesão seja descrita corretamente, inclusive a especificaçáo de se a mesma ocorreu no ambiente de trabalho. Essa escassez de dados dos protocolos reflete-se nos quase 5\% dos prontuários que apresentam informaçôes vagas sobre os acidentes de trabalho. Quando o campo que contém a opção acidente de trabalho foi assinalado apenas com um "x", cerca de 2,01\% do total de avaliaçóes analisadas, considerou-se a avaliação na categoria "vazia". Algumas avaliaçôes ainda apresentavam informações insuficientes, sem especificação da atividade desempenhada: essas representaram $3,62 \%$ do total, classificados na categoria "sem especificação".
Com relaçáo ao setor de serviços gerais, os acidentes ocorridos na amostra analisada representaram $7,85 \%$ do total. De acordo com as diversas atividades que podem ser desenvolvidas, os riscos alteraram-se. Os mais comuns são encontrados nas atividades desenvolvidas em altura, que apresentam risco de queda. Cortes, queimaduras e torçôes configuram-se como as principais lesôes (IRIART et al., 2008). Nacionalmente, os acidentes de trabalho nesse setor compreendem, aproximadamente, $1,8 \%$ dos acidentes ocorridos em um ano. No estado do Paraná, vitimaram 1,2 a cada 100 trabalhadores, no ano de 2009 (ANUÁRIO..., 2012). Não é possível determinar com precisáo qual atividade apresenta maior risco de acidente de trabalho, porém destaca-se que esse setor aparece neste estudo como o terceiro com maiores índices, dada a clientela atendida no Hospital do Trabalhador.

Os acidentados de trabalho do setor de transportes e correios representam $6,24 \%$ do total de atendidos. Segundo Teixeira (2005), os acidentes de trabalho no setor de transportes ocorrem dado os diversos fatores que influenciam a integridade física, social e psicológica dos trabalhadores. Por atuarem profissionalmente em ruas e estradas, conviverem com violência e problemas urbanos, o risco de ocorrerem acidentes aumenta significativamente. No Brasil, segundo Teixeira (2005), muitos acidentes acometem trabalhadores do setor de transportes. Nacionalmente, os acidentes nesse setor representaram 7,4\% do total, em 2012. No estado do Paraná acidentaram-se, em média, 2,52 a cada 100 trabalhadores no setor, no mesmo período (ANUÁRIO..., 2012).

$\mathrm{Na}$ amostra analisada, 5,63\% dos acidentes aconteceram no setor da alimentaçáo. Como fatores de risco para esses acidentes de trabalho destacam-se: o desenvolvimento da atividade em si, dados os riscos para cortes e queimaduras; a falta de manutenção dos equipamentos utilizados, o que pode causar preensões, amputaçóes e choques elétricos; e condiçôes ambientais não adequadas, como serviço de drenagem ineficiente e piso inadequado (CASAROTTO; MENDES, 2003). No Brasil, a ocorrência de acidentes nesse setor é de, aproximadamente, $2,7 \%$. em média, por ano. No estado do Paraná, os acidentes registrados no mesmo setor representam, em média, 1,5 acidentes a cada 100 trabalhadores, para igual período (ANUÁRIO..., 2012).

Outro dado apontado nesta pesquisa refere-se à alta incidência $(86,72 \%)$ de acidentes de trabalho envolvendo trabalhadores do gênero masculino, 
principalmente nos setores construção civil e metalurgia. Pacientes do gênero masculino representaram $86,78 \%$ dos atendimentos, enquanto o gênero feminino representou $13,28 \%$. Tais dados seguem as tendências nacionais, que apontam cerca de 700 mil atendimentos a acidentados de trabalho em 2010, porém cerca de 500 mil atendimentos foram para vítimas do sexo masculino e $198 \mathrm{mil}$ para vítimas do sexo feminino (ANUÁRIO..., 2012).

A pesquisa também destacou a faixa etária dos 21 aos 30 anos como a mais representativa entre os atendidos, totalizando 127 pacientes. Seguindo as estatísticas nacionais, a faixa que apresenta o maior número de acidentes de trabalho vai dos 20 aos 29 anos, que representam em média 177 mil acidentados por ano (ANUÁRIO..., 2012). Portanto, as tendências de ocorrência de acidentes nessa faixa etária e gênero seguem os dados nacionais encontrados.

Ressalta-se também que, nacionalmente, para o gênero feminino, a faixa etária que apresentou o maior número de acidentes vai dos 30 aos 39 anos: nela ocorreram aproximadamente 62 mil acidentes no ano de 2010 (ANUÁRIO..., 2012). Dessa forma, os dados encontrados corroboram as estatísticas nacionais disponíveis, visto que a faixa etária dos 31 aos 40 anos de idade apresentou o maior número de atendimentos do sexo feminino, totalizando 22 pacientes.

Tradicionalmente a análise dos acidentes de trabalho ocorreu em uma concepçáo "unicausal", atribuindo-se os acidentes apenas a falhas humanas. Porém ao expandirem-se os pensamentos sobre a ocorrência dos acidentes de trabalho a uma concepção "multicausal" iniciaram-se as discussōes e percepçôes dos riscos do ambiente de trabalho e de como ocorre a articulação desses elementos estruturais com os trabalhadores (GONÇALVES; DIAS, 2011).

A análise sobre a ocorrência dos acidentes de trabalho bem como dos setores de trabalho em que mais ocorreram esses eventos são um desafio para o profissional que atua nessa perspectiva de vigilância em saúde do trabalhador, uma vez que são insuficientes as formas de coleta de dados por parte dos serviços, como se verificou no analisado nesta pesquisa.

Ressalta-se que esses dados deveriam ser utilizados para a implementação de serviços de vigilância constante nos ambientes de trabalho dos setores que se destacaram com altos índices de acidente no município de Curitiba.

\section{Considerações finais}

A vigilância em saúde do trabalhador possui como prática prevista a investigação e análise de dados referentes aos processos de saúde-trabalho (MACHADO, 1997). O terapeuta ocupacional configura-se como um importante profissional, dada a sua formação ímpar sobre a influência do trabalho na constituição da singularidade e do cotidiano dos indivíduos (LANCMAN; GHIRARDI, 2002).

Dessa forma, a identificação e caracterização da demanda de acidentes de trabalho analisada no ambulatório em questão, por meio deste estudo, permitiu o monitoramento das tendências e causas dos atendimentos a vítimas de acidentes de trabalho em um determinado período de tempo. Além disso, indica-se, nessa perspectiva, que o profissional terapeuta ocupacional pode contribuir para a vigilância em saúde do trabalhador e, inclusive, justificar estatisticamente a implementação de serviços de prevenção à ocorrência dos acidentes de trabalho (LANCMAN et al., 2003).

Para tanto, mostrou-se necessário a criteriosa coleta de dados e informaçóes acerca dos mecanismos da lesão laboral e a fiel descrição das características das atividades de trabalho, bem como o compartilhamento dessas com os órgãos responsáveis pela fiscalização do trabalho.

Espera-se que este estudo represente um estímulo e um convite aos demais profissionais terapeutas ocupacionais para que continuem a investigaçáo sobre a identificação e caracterização dos acidentes de trabalho, demonstrando sua especificidade de atuação nas equipes de assistência aos trabalhadores e unindo esforços para um objetivo comum: a prevenção dos acidentes de trabalho.

\section{Referências}

ABREU, S. E. A. Pesquisa e análise documental. Anápolis: Unievangélica, 2001. Disponível em:

$<$ http://www.unievangelica.edu.br/gc/imagens/ noticias/1817/file/01.pdf>. Acesso em: 14 nov. 2011.

ANUÁRIO Brasileiro de Proteçấ 2012. Revista Proteção, São Paulo, Edição 17, 2012.

BRASIL. Ministério da Saúde. Secretaria de Atenção à Saude. Departamento de Ações Programáticas Estratégicas. Legislação em saúde: Caderno de legislação em saúde do trabalhador. 2. ed. Brasília, 2005. 380 p. (Série E. Legislação de Saúde).

CASAROTTO, R. A.; MENDES, L. F. Queixas, doenças ocupacionais e acidentes de trabalho em trabalhadores de cozinhas industriais. Revista 
Brasileira de Saúde Ocupacional, São Paulo, v. 18, n. 107-108, p. 119-126, 2003. http://dx.doi.org/10.1590/ S0303-76572003000200011

CORDEIRO, R. et al. O sistema de vigilância de acidentes do trabalho de Piracicaba, São Paulo, Brasil. Cadernos de Saúde Pública, Rio de Janeiro, v. 5, n. 21, p. 1574-1583, 2005. Disponível em: <http://www.scielosp. org/pdf/csp/v21n5/31.pdf> Acesso em: 29 abr. 2012. http://dx.doi.org/10.1590/S0102-311X2005000500031

DIAS, E. C.; HOEFEL, M. G. O desafio de implementar as ações de saúde do trabalhador no SUS: a estratégia da RENAST. Ciência \& Saúde Coletiva, Rio de Janeiro, v. 10, n. 4, p. 817-827, 2005. Disponível em: <http:// www.scielosp.org/scielo.php?script $=$ sci_arttext \&pi $\mathrm{d}=$ S141381232005000400007\&lng=pt\&nrm=iso > Acesso em: 03 abr. 2012. http://dx.doi.org/10.1590/ S1413-81232005000400007

GIL, A. C. Métodos e técnicas da pesquisa social. 6. ed. São Paulo: Atlas, 2008.

GONÇALVES, C.; DIAS, A. Três anos de acidentes do trabalho em uma metalúrgica: caminhos para seu entendimento. Ciência \& Saúde Coletiva, Rio de Janeiro, v. 16, n. 2, p. 635-646, 2011. Disponível em: <http://www.scielo.br/scielo.php?script=sci_artt ext \&pid $=S 1413-81232011000200027>$. Acesso em: 30 abr. 2012. http://dx.doi.org/10.1590/ S1413-81232011000200027

HENNINGTON, E. A.; MONTEIRO, M. O perfil epidemiológico dos acidentes de trabalho no Vale dos Sinos e o sistema de vigilância em saúde do trabalhador. História, Ciências, Saúde-Manguinhos, Rio de Janeiro, v. 13, n. 4, p. 865-876, 2006. Disponível em: < http://www.scielo.br/scielo.php?script=sci_artt ext \&pid $=S 0104-59702006000400005>$. Acesso em: 21 jun. 2012. http://dx.doi.org/10.1590/ S0104-59702006000400005

IRIART, J. A. B. et al. Representaçóes do trabalho informal e dos riscos à saúde entre trabalhadoras domésticas e trabalhadores da construção civil. Ciência \& Saúde Coletiva, Rio de Janeiro, v. 13, n. 1, p. 165-174, fev. 2008. Disponível em: <http:// www.scielo.br/scielo.php?script $=$ sci_arttext \&p $\mathrm{id}=$ S1413-81232008000100021 $>$. Acesso em: 04 fev. 2013. http://dx.doi.org/10.1590/S1413-81232008000100021

LANCMAN, S. et al. Informar e refletir: uma experiência de terapia ocupacional na prevenção de riscos à saúde do trabalhador. Revista de Terapia Ocupacional da Universidade de São Paulo, São Paulo, v. 14, n. 1, p. 1-9, 2003. Disponível em: <http://www.revistas.usp.br/rto/ article/view/13909>. Acesso em: 20 abr. 2012.

LANCMAN, S.; GHIRARDI, M. I. G. Pensando novas práticas em terapia ocupacional, saúde e trabalho. Revista de Terapia Ocupacional da Universidade de São Paulo, São Paulo, v. 13, n. 2, p. 44-50, maio/ago., 2002.

LOPES FILHO, J. D. et al. Análise de algumas variáveis relacionadas aos acidentes de trabalho e suas implicações. Arquivos Médicos do ABC, Santo André, v. 10, n. 1/2, p.
25-29, 1987. Disponível em: <http://site.fmabc.br/admin/ files/revistas/10amabc25.pdf>. Acesso em: 14 nov. 2011.

LOURENÇO, E. A.; BERTANI, I. F. Saúde do trabalhador no SUS: Desafios e perspectivas frente à precarização do trabalho, Revista Brasileira de Saúde Ocupacional, São Paulo, v. 32, n. 115, p. 121-134, 2007. Disponível em: <http://www.scielo.br/scielo. php? pid $=$ S0303-76572007000100011\&script $=$ sci abstract\&tlng=pt>. Acesso em: 14 out. 2011.

MACHADO, J. M. H. Processo de vigilância em saúde do trabalhador. Cadernos de Saúde Pública, Rio de Janeiro, v. 13, p. 33-45, 1997. Suplemento 2. Disponível em: <http://www.scielosp.org/pdf/csp/v13s2/1362.pdf>. Acesso em: 29 abr. 2012. http://dx.doi.org/10.1590/ S0102-311X1997000600004

NASCIMENTO, L. M. B. Análise Documental e Análise Diplomática: Perspectivas de interlocução de procedimentos. 2009. 198 f. Tese (Doutorado em Ciência da Informação)-Programa de Pós-Graduação em Ciência da Informação, Faculdade de Filosofia e Ciências, Universidade Estadual Paulista Júlio de Mesquita Filho, Marília, 2009. Disponível em: <http://www.marilia. unesp.br/Home/Pos-Graduacao/CienciadaInformacao/ Dissertacoes/nascimento_lmb_do_mar.pdf $>$. Acesso em: 14 nov. 2011.

ROCHA, J. S. Y. A Gestão da Saúde no Brasil. Ribeirão Preto: Universidade de São Paulo, 2002. Disponível em: <http://www.governoemrede.sp.gov. br/ead/saude/Apostilas/modulo_02/sessao_6/parte_1/ gestao_da_saude.pdf>. Acesso em: 16 abr. 2012.

SANTANA, V. S. et al. A utilização de serviços de saúde por acidentados de trabalho. Revista Brasileira de Saúde Ocupacional, São Paulo, v. 32, n. 115, p. 135-143, 2007. Disponível em: <http://www.scielo.br/scielo. php? pid $=$ S0303-76572007000100012\&script $=$ sci arttext $>$. Acesso em: 14 nov. 2011. http://dx.doi. org/10.1590/S0303-76572007000100012

SANTANA, V.; OLIVEIRA, R. Saúde e trabalho na construção civil em uma área urbana do Brasil. Cadernos de Saúde Pública, Rio de Janeiro, v. 20, n. 3, p. 797-811, 2004. http://dx.doi.org/10.1590/ S0102-311X2004000300017

SANTOS, M. C. Reabilitação física, terapia ocupacional e saúde do trabalhador. In: LANCMAN, S. Saúde, trabalho e terapia ocupacional. São Paulo: Roca, 2004. cap. 5. p. 99-114.

TEIXEIRA, M. L. P. Acidentes e doenças do trabalho de profissionais do setor de transportes: Análise dos motoristas do Estado de São Paulo, 1997-1999. 2005. 115 f. Dissertação (Mestrado em Saúde Pública)-Faculdade de Saúde Pública, Universidade de São Paulo, São Paulo, 2005.

VILELA, R. D. G. et al. Acidente do trabalho investigado pelo CEREST Piracicaba: Confrontando a abordagem tradicional da segurança do trabalho. Revista Brasileira de Saúde Ocupacional, São Paulo, v. 32, n. 115, p. 29-40, 2007. Disponível em: <http://www.scielo.br/scielo. 
php?pid=S0303-76572007000100004\&script $=$ sci_ arttext>. Acesso em: 14 nov. 2011.

VILELA, R. A. G. Vigilância em saúde do trabalhador e produção acadêmica: Uma articulação dispensável. Ciência \& Saúde Coletiva, Rio de Janeiro, v. 16, n. 8, p. 3369-3372, 2011. Disponível em: <http://www.scielo.br/ pdf/csc/v16n8/a03v16n8.pdf>. Acesso em: 21 jun. 2012. http://dx.doi.org/10.1590/S1413-81232011000900003
WATANABE, M.; GONÇALVES, R. M. Relações conceituais entre Terapia Ocupacional e Ergonomia. In: LANCMAN, S. Saúde, trabalho e Terapia Ocupacional. São Paulo: Roca, 2004. cap. 2. p.19-71.

WÜNSCH FILHO, V. Reestruturação produtiva e acidentes de trabalho no Brasil: Estrutura e tendências. Cadernos Saúde Pública, Rio de Janeiro, v. 15, n. 1, p. 41-51, 1999. Disponível em:<http://www.scielosp.org/ pdf/csp/v15n1/0034.pdf>. Acesso em: 30 abr. 2012. http://dx.doi.org/10.1590/S0102-311X1999000100005

\section{Contribuição dos Autores}

Marcela Balsano foi responsável pela concepção e organização do texto, coleta e análise dos dados e confecção dos gráficos apresentados. Angela Simonelli foi responsável pela revisão do texto, organização e análise dos dados coletados e orientações.

\section{Notas}

${ }^{1}$ Texto elaborado a partir da participação no programa de iniciação científica da Universidade Federal do Paraná, edital PIBIC 2012-2013, BANPESQ 201202604. Projeto de pesquisa submetido e aprovado pelo Comitê de Ética em Pesquisa em Seres Humanos do Hospital do Trabalhador. 